\title{
Immediate and delayed photoactivation of self-adhesive resin cements and retention of glass-fiber posts
}

\begin{abstract}
André Luis FARIA-E-SILVA(a) Aline Carvalho PEIXOTO(a) Marcela Gonçalves BORGES (b) Murilo de Sousa MENEZES(b) Rafael Ratto de MORAES(c)
\end{abstract}

(a) Department of Dentistry, School of Dentistry, Universidade Federal de Sergipe UFS, Aracaju, SE, Brazil.

(b) Department of Restorative Dentistry and Dental Materials, School of Dentistry, Universidade Federal de Uberlândia - UFU, Uberlândia, MG, Brazil.

(c) Department of Restorative Dentistry, School of Dentistry, Universidade Federal de Pelotas - UFPel, Pelotas, RS, Brazil.
Declaration of Interests: The authors certify that they have no commercial or associative interest that represents a conflict of interest in connection with the manuscript.

\section{Corresponding Author:}

André Luis Faria-e-Silva

E-mail: fariaesilva.andre@gmail.com

http://dx.doi.org/10.1590/S1806-83242014.50000005 Epub Jan 24, 2014
Submitted: Jun 11, 2013

Accepted for publication: Nov 13, 2013

Last revision: Nov 28, 2013

\begin{abstract}
The aim of this study was to evaluate the effect of immediate and delayed photoactivation of self-adhesive resin cements (SARCs) on the retention of glass-fiber posts luted into root canals. Bovine incisors were endodontically treated, and post holes of $9 \mathrm{~mm}$ in depth were prepared. Fiber posts were luted using one of two SARCs, BisCem ${ }^{\circledR}$ (Bisco Inc., Schaumburg, USA) or RelyX Unicem clicker (3M ESPE, Saint Paul, USA), or a regular (etch-and-rinse) resin cement (AllCem; FGM, Joinvile, Brazil). Photoactivation was performed immediately, or at 5 or $10 \mathrm{~min}$ after cementation. Root/post specimens were transversely sectioned 7 days after luting into 1-mm-thick slices, which were submitted to push-out testing in a mechanical testing machine. Bond strength data were analyzed by two-way ANOVA and Student-Newman-Keuls' method $(\alpha=0.05)$. Immediate photoactivation resulted in the highest bond strength for Unicem. BisCem ${ }^{\circledR}$ demonstrated higher bond strength values when photoactivated after a 10-min delay. Immediate photoactivation yielded the lowest bond strengths for AllCem, although no differences in bond strength were observed between photoactivation delayed by 5 and $10 \mathrm{~min}$. In conclusion, the moment of resin cement photoactivation may affect the intraradicular retention of fiber posts, depending upon the resin cement used for luting.
\end{abstract}

Descriptors: Dental Bonding; Post and Core Technique; Resin Cement.

\section{Introduction}

The elastic modulus of glass-fiber posts (GFPs) is similar to that of dentin. Consequently, the use of GFPs for restoring endodontically treated teeth is considered advantageous, as it reduces the risk of root fractures. Moreover, failures with GFPs tend to be less severe compared to those with rigid posts. ${ }^{1-3}$ Proper bonding of GFPs to intraradicular dentin is essential for the longevity of restorative procedures. Most failures of GFP-retained restorations result from debonding (decementation), with the cement/dentin interface being the weakest link in the bonded assembly. ${ }^{3-6}$ Another commonly reported failure is fracture of the post or core, which may result from an initial debonding of the luted post from the root canal. ${ }^{4}$

Due to the complexity of luting procedures using multiple-step adhesive systems, self-adhesive resin cements (SARCs) are gaining popularity. SARCs are designed for use in a single clinical step, with no application 
of primer or bonding resin to the dental substrates. SARCs are formulated with acid-functionalized monomers that are able to demineralize and infiltrate the tooth tissues. ${ }^{7}$ In addition to mechanical interlocking, the bonding mechanism of SARCs is also attributed to a chemical reaction between the acidic methacrylates and hydroxyapatite..$^{8-9}$

SARCs are hydrophilic and have an acidic character, especially in the initial moments after component mixing. These characteristics are important for proper wetting and surface etching, aiding the interaction of SARCs with dental tissues. ${ }^{7}$ Due to reactions between the SARC acidic monomers and calcium ions on the tooth, as well as the presence of alkaline ions leached from the acid-soluble glass particles in the SARC, the SARC materials become more hydrophobic with time. The pH-buffering effect is important to permit adequate polymerization of the SARCs and to improve their mechanical stability. ${ }^{10,11}$

All commercially available SARCs are dualcured, allowing both auto- and photo-initiation of the polymerization reaction. ${ }^{7}$ Based on the bonding mechanism and the importance of $\mathrm{pH}$-buffering for polymerization, a time delay between the cement mixing and photoactivation (polymerization) steps may favor the ability of SARCs to bond to dentin. ${ }^{12}$ A rapid increase of cement viscosity by light irradia$\operatorname{tion}^{13}$ may hinder the reaction of the acidic monomers with the dental tissues, which may affect the bonding mechanism. Although delaying the photoactivation may not increase the polymerization potential of resin-based cements, ${ }^{14}$ delayed photoactivation of dual-cured resin cements has been shown, in some cases, to reduce polymerization stress. ${ }^{15}$

The aim of this study was to evaluate the effect of the moment of photoactivation (immediate or delayed) of SARCs on the retention of GFPs luted to root canals. An etch-and-rinse resin cement was tested as a reference. The study hypothesis was that delayed photoactivation would increase GFP retention.

\section{Methodology}

This in vitro study involved a $3 \times 3$ factorial design $(\mathrm{n}=8$ per group). The factors under evaluation were:

- resin cement (three levels: one etch-and-rinse resin cement and two SARCs) and
Table 1. Composition of the resin cements tested.

\begin{tabular}{|c|c|c|}
\hline $\begin{array}{l}\text { Resin } \\
\text { cement }\end{array}$ & Main components* & $\begin{array}{c}\text { Lot number } \\
\text { (expiration } \\
\text { date) }\end{array}$ \\
\hline $\begin{array}{l}\text { BisCem } \\
\text { (self- } \\
\text { adhesive) }\end{array}$ & $\begin{array}{l}\text { Base paste: bisphenol-A glycidyl } \\
\text { dimethacrylate, uncured } \\
\text { dimethacrylate monomer, } \\
\text { glass filler } \\
\text { Catalyst paste: phosphate acidic } \\
\text { monomer, glass fillers }\end{array}$ & $\begin{array}{c}1000007677 \\
\text { (Mar/2012) }\end{array}$ \\
\hline $\begin{array}{l}\text { Unicem } \\
\text { (self- } \\
\text { adhesive) }\end{array}$ & $\begin{array}{l}\text { Base paste: methacrylate } \\
\text { monomers containing acid groups, } \\
\text { methacrylate monomers, silanated } \\
\text { fillers, initiator components, } \\
\text { stabilizer } \\
\text { Catalyst paste: methacrylate } \\
\text { monomer, alkaline fillers, silanated } \\
\text { fillers, initiator components }\end{array}$ & $\begin{array}{c}1031000234 \\
(\text { Feb/2012) }\end{array}$ \\
\hline $\begin{array}{l}\text { AllCem } \\
\text { (regular) }\end{array}$ & $\begin{array}{l}\text { Base/catalyst pastes: bisphenol-A } \\
\text { glycidyl dimethacrylate, ethoxylated } \\
\text { bisphenol-A dimethacrylate, } \\
\text { triethyleneglycol dimethacrylate, } \\
\text { inorganic fillers, initiator } \\
\text { components, stabilizer }\end{array}$ & $\begin{array}{c}100511 \\
(\text { Nov/2012) }\end{array}$ \\
\hline
\end{tabular}

*As provided by the manufacturers.

- moment of photoactivation (three levels: immediately, and after a 5- or 10-min delay).

The SARCs tested were RelyX Unicem clicker (3M ESPE, St. Paul, USA) and BisCem ${ }^{\circledR}$ (Bisco, Schaumburg, USA), while the regular resin cement tested was AllCem (FGM, Joinvile, Brazil). Table 1 depicts the compositions of the luting agents. The resin cements were used to lute translucent GFPs (White Post DC3; FGM) into the root canals of bovine incisors. The response variables were push-out bond strength (MPa) to intraradicular dentin and failure mode.

In total, 72 bovine incisors with mature apices and straight roots were used. The crowns were removed to standardize a 14-mm root height. Roots with canals of a larger diameter than the drill of the post kit were discarded. For endodontic treatment, a step-back preparation technique was used with stainless steel K-files (Dentsply/Maillefer, Ballaigues, Switzerland) and \#2 to \#4 Gates-Glidden drills (Dentsply/Maillefer). All enlargement procedures were performed under irrigation with 2.5\% sodium hypochlorite $(\mathrm{NaOCl})$ solution. Prepared root canals were filled with gutta-percha cones and resin sealer (Sealer-26; Dentsply Caulk, Milford, 
USA) by the lateral condensation technique. Filled roots were stored in $100 \%$ relative humidity for $72 \mathrm{~h}$ to set the resin sealer. Post holes measuring $9 \mathrm{~mm}$ in length were prepared by using the drills in the post kit. Post surfaces were etched by immersion in $24 \%$ hydrogen peroxide $\left(\mathrm{H}_{2} \mathrm{O}_{2}\right)$ for $1 \mathrm{~min}^{16}$ and silanized (RelyX Ceramic Primer; 3M ESPE).

Intraradicular dentin was treated with $5 \% \mathrm{NaOCl}$ for $60 \mathrm{~s}$ before insertion of the SARCs into the canals. For AllCem, the intraradicular dentin was etched with $37 \%$ phosphoric acid for $15 \mathrm{~s}$ and rinsed; excess dentin moisture was removed using absorbent paper cones. A two-step, etch-and-rinse adhesive (Ambar; FGM) was applied, the solvent was evaporated for 20 $\mathrm{s}$, and photoactivation was performed for $20 \mathrm{~s}$ using a light-emitting diode unit (Radii Cal; SDI, Victoria, Australia) with an irradiance of $600 \mathrm{~mW} / \mathrm{cm}^{2}$.

All cements were mixed for $10 \mathrm{~s}$ and inserted into the root canals using a Centrix syringe (DFL, Rio de Janeiro, Brazil). Posts were inserted using light hand pressure, and excess luting material was removed. Photoactivation of the cements was performed immediately, $5 \mathrm{~min}$, or $10 \mathrm{~min}$ after insertion of the GFP into the root canal. The light-guide tip of the curing unit was positioned in the cervical portion of the root, and photoactivation was carried out for $40 \mathrm{~s}$ at the buccal and lingual faces.

After storage in distilled water at $37^{\circ} \mathrm{C}$ for 1 week, each root was sectioned into 6 slabs (1-mm thickness). Slabs were observed under an optical microscope (DFC 280; Leica Microsystems, Wetzlar, Germany) at $40 \times$ magnification. Dimensions (radius and perimeter) of the top and bottom surfaces of the post were recorded to calculate the lateral area of the GFP in each slab. The slabs were positioned on a push-out jig in a mechanical testing machine (model 4411; Instron, Canton, USA). A compressive load was applied at a crosshead speed of $0.5 \mathrm{~mm} / \mathrm{min}$ until the post was dislodged. The push-out bond strength values (MPa) were calculated by dividing the maximum load by the lateral area of the GFP. Bond strength values of all slabs from the same root were averaged.

Fractured specimens were observed under $40 \times$ magnification to classify the failure modes. A type I or mixed failure was defined as failure at the resin cement/ post interface and at the resin cement / dentin
Table 2. Means (standard deviations) for push-out bond strength, $\mathrm{MPa}(\mathrm{n}=8)$.

\begin{tabular}{l|c|c|c}
\hline \multirow{2}{*}{$\begin{array}{l}\text { Moment of } \\
\text { light-activation }\end{array}$} & \multicolumn{3}{|c}{ Resin cement } \\
\cline { 2 - 4 } & BisCem & Unicem & AllCem \\
\hline Immediate & $4.2(1.4) \mathrm{B}, \mathrm{c}$ & $12.1(2.5) \mathrm{A}, \mathrm{a}$ & $7.6(2.5) \mathrm{B}, \mathrm{b}$ \\
\hline After $5 \mathrm{~min}$ & $5.5(2.1) \mathrm{B}, \mathrm{b}$ & $9.0(1.9) \mathrm{B}, \mathrm{a}$ & $10.7(3.0) \mathrm{A}, \mathrm{a}$ \\
\hline After $10 \mathrm{~min}$ & $12.8(4.0) \mathrm{A}, \mathrm{a}$ & $6.8(2.1) \mathrm{B}, \mathrm{b}$ & $10.8(3.1) \mathrm{A}, \mathrm{a}$ \\
\hline
\end{tabular}

Distinct uppercase letters in the same column indicate differences between moments of light activation; distinct lowercase letters in the same line indicate differences between materials $(p<0.05)$.

interface. A type II failure was defined as an adhesive failure between the resin cement and root dentin. The root was considered as the experimental unit in the statistical analysis. Data were analyzed using twoway analysis of variance (ANOVA) (resin cement $x$ moment of photoactivation). All pair-wise multiple comparison procedures were carried out using the Student-Newman-Keuls' method $(\alpha=0.05)$. Statistical analysis was performed using SigmaStat statistical software version 3.5 (Systat Software, Point Richmond, USA). Failure mode data for each cement were analyzed using chi-square tests $(\alpha=0.05)$.

\section{Results}

Results for bond strength are shown in Table 2. Values are reported independent of the root third because no significant differences were observed between the root portions for any group. Significant effects were found for the following factors: "moment of photoactivation" ( $p=0.012)$ and "cement" $(p=0.014)$, and for the interaction between these two factors $(p<0.001)$.

Photoactivation after a 10-min delay resulted in a significantly higher bond strength for BisCem ${ }^{\circledR}$ compared to the other groups. Immediate photoactivation of Unicem resulted in a significantly higher bond strength compared to photoactivation at both delayed times. For AllCem, a photoactivation delay of 5 or 10 min yielded a significantly higher bond strength compared to immediate photoactivation. After immediate photoactivation, Unicem demonstrated a significantly higher bond strength than those of the other cements, whereas BisCem ${ }^{\circledR}$ showed the lowest bond strength values. When photoactivated after a 5-min delay, Unicem and AllCem showed simi- 
Table 3. Distribution of failure modes among groups.

\begin{tabular}{l|c|c|c}
\hline \multirow{3}{*}{ Cement } & \multirow{2}{*}{$\begin{array}{c}\text { Moment of } \\
\text { light-activation }\end{array}$} & \multicolumn{2}{|c}{ Failure modes*, \% } \\
\cline { 3 - 4 } & Immediate & 26.8 & 73.2 \\
\hline \multirow{3}{*}{ BisCem } & After 5 min & 31.9 & 68.1 \\
\cline { 2 - 4 } & After 10 min & 45.5 & 54.5 \\
\hline \multirow{4}{*}{ Unicem } & Immediate & 38.1 & 61.9 \\
\cline { 2 - 4 } & After 5 min & 27.9 & 72.1 \\
\hline \multirow{4}{*}{ AllCem } & After 10 min & 26.5 & 73.5 \\
\hline & Immediate & 40.5 & 59.5 \\
\cline { 2 - 4 } & After 5 min & 60.0 & 40.0 \\
\cline { 2 - 4 } & After 10 min & 50.0 & 50.0 \\
\hline
\end{tabular}

*Type I: mixed failure involving failure at the resin cement/post interface and at the resin cement/dentin interface; Type II: adhesive failure between resin cement and root dentin.

lar bond strengths, which were higher than those of BisCem ${ }^{\circledR}$ after the same delay. When photoactivated after a 10-min delay, BisCem ${ }^{\circledR}$ and AllCem showed significantly higher bond strengths than that shown by Unicem.

Results for failure modes are shown in Table 3. For BisCem ${ }^{\circledR}$ and Unicem, a predominance of adhesive failures (Type II) was observed for all photoactivation times. An increase in mixed failures (Type I) was observed for BisCem ${ }^{\circledR}$ in the 10-min delay group. AllCem demonstrated a higher frequency of mixed failures than the SARCs. Adhesive failures between resin cement and post were not observed for any group. Chi-square tests indicated no significant effect of the moment of photoactivation on failure modes for AllCem $(p=0.261)$ and Unicem $(p=0.44)$, but did show a significant effect for $\operatorname{BisCem}^{\circledast}(p=0.018)$.

\section{Discussion}

The tested hypothesis was rejected because the delayed photoactivation increased the retention of the GFPs only for BisCem ${ }^{\circledR}$ and AllCem. Improved bond strength for delayed photoactivation times was expected based on three main mechanisms. First, the delayed light exposure and the consequent delay in polymer vitrification would allow more time for a chemical reaction between the phosphate methacrylates of the polymerizing cement and the dentin hydroxyapatite. Second, the prolonged reaction of the phosphate monomers with calcium would buffer the initially low $\mathrm{pH}$ of the SARCs, leading to a higher degree of carbon double bond $(\mathrm{C}=\mathrm{C})$ conversion of the cements and, subsequently, improved mechanical properties. ${ }^{10,17}$ Third, delayed photoactivation decreases the polymerization stress ${ }^{15}$ which may improve the bonding of the cement to the root canal.

The impact of the moment of photoactivation was material-dependent. A negative effect of delaying photoactivation was observed for Unicem. This finding suggests that factors other than polymerization stress and the time for the chemical reaction of the acidic monomers with dentin may interfere with the bonding of SARCs (e.g., differences in viscosity and flow of the resin cements). The post holes were irrigated with $\mathrm{NaOCl}$ before cement insertion, to remove the smear layer. The post hole smear layer has been shown to be thicker than that observed in coronal cavities, ${ }^{18}$ which may hinder the interaction of SARCs with the underlying dentin, particularly for materials with higher viscosity. Despite the increased contact of the cement with the dentin after $\mathrm{NaOCl}$ treatment, $\mathrm{NaOCl}$ alterations on the substrate may also interfere with the bonding ability of some SARCs. Irrigation with $\mathrm{NaOCl}$ leaves residual oxygen on the substrate, which may interfere with the free-radical polymerization of Unicem at the bonded interface. ${ }^{19}$ The same result, however, was not observed for BisCem, most likely due to differences in polymerization kinetics between the SARCs.

Even with the use of translucent GFPs, the light intensity reaching the deepest areas of the root canal is reduced, ${ }^{20,21}$ which magnifies the role of the selfactivation agents on the $\mathrm{C}=\mathrm{C}$ conversion of SARCs. The negative effect of residual oxygen is expected to be more apparent in cases of slower self-cure; thus, longer delay times before photoactivation may increase the inhibition of polymerization by residual oxygen. In a previous study, BisCem ${ }^{\circledR}$ reached only $6 \%$ of $C=C$ conversion at $10 \mathrm{~min}$ when left to polymerize in the self-cure mode, ${ }^{22}$ whereas Unicem achieved $30 \%$ of $\mathrm{C}=\mathrm{C}$ conversion in the same time. Considering that the self-cure potential of BisCem $^{\circledR}$ is minimal, limiting the self-cure reaction would not significantly affect the final conversion or bonding ability. In contrast, limiting the self-cure reaction of Unicem may significantly reduce mono- 
mer conversion, which may explain the reduction in bond strength of Unicem when photoactivation was delayed. The residual oxygen did not affect the bond strength of AllCem, most likely because the adhesive layer was applied to the intraradicular dentin before cementation.

The failure mode findings corroborate the timedependent effect of residual oxygen on cement polymerization. For Unicem, a trend toward increased adhesive failures was observed with delayed photoactivation, despite the absence of statistical significance. This finding suggests that the cement polymerization was affected at the bonded interface, most likely due to the effect of residual oxygen. On the other hand, BisCem ${ }^{\circledR}$ showed a trend toward increased mixed failures with delayed photoactivation. Prolonged time before photoactivation likely allowed a more efficient chemical reaction between the cement and dentin, which buffered the $\mathrm{pH}$ of the cement and improved its polymerization and bonding potential, due to a more effective chelation of calcium ions. AllCem showed a similar distribution of failure modes regardless of the moment of photoactivation, which is again explained by the presence of an adhesive layer on the intraradicular dentin.

\section{References}

1. Chuang SF, Yaman P, Herrero A, Dennison JB, Chang CH. Influence of post material and length on endodontically treated incisors: an in vitro and finite element study. J Prosthet Dent. 2010 Dec;104(6):379-88.

2. Costa RG, Morais EC, Campos EA, Michel MD, Gonzaga CC, Correr GM. Customized fiber glass posts. Fatigue and fracture resistance. Am J Dent. 2012 Feb;25(1):35-8.

3. Ferrari M, Vichi A, Fadda GM, Cagidiaco MC, Tay FR, Breschi $\mathrm{L}$, et al. A randomized controlled Trial of endodontically treated and restored premolars. J Dent Res. 2012 Jul;91(7 Suppl):72S-78S.

4. Santos AF, Meira JB, Tanaka CB, Xavier TA, Ballester RY, Lima RG, et al. Can fiber posts increase root stresses and reduce fracture?. J Dent Res. 2010 Jun;89(6):587-91.

5. Schmitter M, Hamadi K, Rammelsberg P. Survival of two post systems - five-year results of a randomized clinical trial. Quintessence Int. 2011 Nov-Dec;42(10):843-50.
The results of the present study indicate that the moment of photoactivation of resin cement may affect the intraradicular retention of GFPs, depending on the resin cement used for luting. Delaying photoactivation may pose a risk of a possible deleterious effect of the irrigation with $\mathrm{NaOCl}$ used to remove the smear layer from the root canal. A recent systematic review of in vitro studies showed that SARC use may improve the retention of GFPs into root canals. ${ }^{23}$ However, clinicians should be aware of the possible influence that the interaction between irrigation protocols, type of SARC or other cement used, and moment of photoactivation may have on the retention of GFPs.

\section{Conclusion}

Delayed photoactivation of SARCs improved the retention of GFPs to root canals luted with BisCem ${ }^{\circledR}$ or AllCem. However, delaying the photoactivation reduced the bond strength when Unicem was tested.

\section{Acknowledgements}

This study was supported by CNPq (Conselho Nacional de Desenvolvimento Científico e Tecnológico), grant \# 472216/2010-4.

6. Bitter K, Perdigão J, Exner M, Neumann K, Kielbassa A, Sterzenbach G. Reliability of fiber post bonding to root canal dentin after simulated clinical function in vitro. Oper Dent. 2012 Jul-Aug;37(4):397-405.

7. Ferracane JL, Stansbury JW, Burke FJ. Self-adhesive resin cements - chemistry, properties and clinical considerations. J Oral Rehabil. 2011 Apr;38(4):295-314.

8. Gerth HUB, Dammaschke T, Zuchner H, Schafer E. Chemical analysis and bonding reaction of RelyX Unicem and Bifix composites - a comparative study. Dent Mater. 2006 Oct;22(10):934-41.

9. Al-Assaf K, Chakmakchi M, Palaghias G, Karanika-Kouma A, Eliades G. Interfacial characteristics of adhesive luting resins and composites with dentine. Dent Mater. 2007 Jul;23(7):829-39.

10. Zorzin J, Petschelt A, Ebert J, Lohbauer U. pH neutralization and influence on mechanical strength in self-adhesive resin luting agents. Dent Mater. 2012 Jun;28(6):672-9. 
11. Macedo VC, Souza NA, Silva AF, Cote C, Silva C, Martinelli $\mathrm{M}$, et al. Pullout bond strength of fiber posts luted to different depths and submitted to artificial aging. Oper Dent. 2013 Jul-Aug;38(4):E1-6.

12. Khoroushi M, Karvandi TM, Sadeghi R. Effect of prewarming and/or delayed light activation on resin-modified glass ionomer bond strength to tooth structures. Oper Dent. 2012 Jan-Feb;37(1):54-62.

13. Feng L, Suh BI. A mechanism on why slower polymerization of a dental composite produces lower contraction stress. J Biomed Mater Res B Appl Biomater. 2006 Jul;78(1):63-9.

14. Moraes RR, Faria-e-Silva AL, Ogliari FA, Correr-Sobrinho L, Demarco FF, Piva E. Impact of immediate and delayed light activation on self-polymerization of dual-cured dental resin luting agents. Acta Biomater. 2009 Jul;5(6):2095100.

15. Faria-e-Silva A, Boaro L, Braga R, Piva E, Arias V, Martins L. Effect of immediate or delayed light-activation on curing kinetics and shrinkage stress of dual-cure resin cement. Oper Dent. 2011 Mar-Apr;36(2):196-204.

16. Menezes MS, Queiroz EC, Soares PV, Faria-e-Silva AL, Soares CJ, Martins LR. Fiber post etching with hydrogen peroxide: effect of concentration and application time. J Endod. 2011 Mar;37(3):398-402.
17. Madruga FC, Ogliari FA, Ramos TS, Bueno M, Moraes RR. Calcium hydroxide, $\mathrm{pH}$-neutralization and formulation of model self-adhesive resin cements. Dent Mater. 2013 Apr;29(4):413-8.

18. Violich DR, Chandler NP. The smear layer in endodontics - a review. Int Endod J. 2010 Jan;43(1):2-15.

19. Cunha LF, Furuse AY, Mondelli RF, Mondelli J. Compromised bond strength after root dentin deproteinization reversed with ascorbic acid. J Endod 2010 Jan;36(1):130-4.

20. Faria-e-Silva AL, Arias VG, Soares LE, Martin AA, Martins LR. Influence of fiber-post translucency on the degree of conversion of a dual-cured resin cement. J Endod. 2007 Mar;33(3):303-5.

21. Reginato CF, Oliveira AS, Kaizer MR, Jardim PS, Moraes RR. Polymerization efficiency through translucent and opaque fiber posts and bonding to root dentin. J Prosthodont Res. 2013 Jan;57(1):20-3.

22. Moraes RR, Boscato N, Jardim PS, Schneider LF. Dual and self-curing potential of self-adhesive resin cements as thin films. Oper Dent. 2011 Nov-Dec;36(6):635-42.

23. Sarkis-Onofre R, Skupien JA, Cenci MS, Moraes RR, PereiraCenci $T$. The role of resin cement on bond strength of glassfiber posts (GFPs) luted into root canals: a systematic review and meta-analysis of in vitro studies. Oper Dent. 2013. Epub ahead of print. DOI: 10.2341/13-070-LIT. 